Supporting Information for

\title{
Facile in Situ Silver Nanoparticle Formation in Insulating Porous
}

\section{Polymer Matrices}

Sandra Rifai, Craig A. Breen, ${ }^{\dagger}$ Daniel J. Solis, ${ }^{\dagger}$ and Timothy M. Swager ${ }^{*}$

Department of Chemistry, Massachusetts Institute of Technology, Cambridge, Massachusetts 02139 (USA)

\section{Experimental}

Materials: Bis(4-fluorophenyl) sulfone (99\%), bisphenol A (>99\%), poly(phosphoric acid), chloroform, $N, N$-dimethylacetamide (99.8\%, anhydrous), $N, N$-dimethylformamide, and methanol were purchased from Aldrich Chemical Co. (Milwaukee, WI) and used as received. Silver perchlorate (anhydrous), silver trifluoromethanesulfonate (99\%), 4fluorobenzoic acid (99\%), hydrazine (98.5\%), and hydrazine sulfate, ACS, (99\%) were purchased from Alfa Aesar (Ward Hill, MA) and used as received. Potassium carbonate and acetic anhydride were purchased from Mallinckrodt Baker (Paris, KY) and used as received. Poly(acrylic acid) (25\% $\mathrm{M} \mathrm{H}_{2} \mathrm{O}$, MW 90K) was purchased from Polysciences (Warrington, PA). Tetrahydrofuran was collected from a dry still (activated alumina) and stored over $4 \AA$ sieves.

\section{General Sample Preparation}

Microwave Nanoparticle Synthesis: $2.5 \mathrm{mg}$ of aqueous $\mathrm{AgClO}_{4}$ (microliter amounts) was added to a PAE solution prepared in DMF $(0.25 \mathrm{mg} / \mathrm{mL})$. The reaction mixture was transferred to a glass vial (10 mL volume) and placed into a conventional microwave oven (CEM Discover) at room temperature. The sample was heated at $85{ }^{\circ} \mathrm{C}$ for varying time intervals (e.g., starting with 10 s pulses, then 20, 30, . ., $90 \mathrm{~s}$ ), followed by heating at $100{ }^{\circ} \mathrm{C}$ and $125{ }^{\circ} \mathrm{C}$ in the same manner. The reaction vessel was cooled in an ice bath between each pulse; aliquots were taken for measuring UV-visible spectra in a $1 \mathrm{~mm}$ optical path length quartz cuvette. A characteristic color change (from pale yellow to orange) was observed with increased irradiation time and nanoparticle formation.

\section{Polymer-Nanoparticle Thin Films:}

PAE-Oxa- $\mathrm{SO}_{2}$ films - $10 \mathrm{mg}$ of polymer was reacted with an equimolar ratio (relative to the oxadiazole monomer content) of $\mathrm{AgOSO}_{2} \mathrm{CF}_{3}(\sim 1.5 \mathrm{mg})$ in THF for 30 minutes. The solvent was removed by rotary evaporation and the residual composite was dried under vacuum. The polymer-silver ion material was then dissolved into $1 \mathrm{~mL}$ of $\mathrm{CHCl}_{3}$ and thin films were spin cast onto glass (Velocity: $1 \mathrm{~K}$ revolutions $\mathrm{min}^{-1}$; Acceleration: $10 \mathrm{~K}$ revolutions min. $^{-1}$ sec. $^{-1}$; Duration: $60 \mathrm{~s}$ ).

Sulfonated PAE films - Thin sulfonated PAE-silver ion films were spin cast onto glass slides (Velocity: $3 \mathrm{~K}$ revolutions $\mathrm{min}^{-1}$; Acceleration: $10 \mathrm{~K}$ revolutions $\mathrm{min}^{-1} \mathrm{sec}^{-1}$; Duration: $60 \mathrm{~s}$ ) directly from THF (10 mg PAE + $1.3 \mathrm{mg} \mathrm{AgOSO}_{2} \mathrm{CF}_{3} / \mathrm{mL}$ ). 
Each film was suspended over an aqueous hydrazine solution (10 \% hydrazine) for 3 minutes in order to induce nucleation. As a result of nanoparticle formation, the transparent film adopted a brown tint. UV-visible spectra of the films were taken before and after exposure to hydrazine.

Transmission Electron Microscopy Samples: The nanoparticle stabilized PAE in DMF solutions were dropped onto carbon coated copper grids and dried under vacuum. Thin film samples for TEM imaging were prepared by first carbon coating the PAE-metal films (200 A). Next, droplets of poly(acrylic acid) (PAA) were pipetted onto the films, which were then cured overnight at $50{ }^{\circ} \mathrm{C}$. A razor blade was used to lift the PAA drops (with the polymer film attached) off of the glass slide. The droplets were placed in water with the PAA face down so that the acid could dissolve, while the carbon film kept the polymer film stable. Finally, the films were picked up with carbon coated copper TEM grids (Ladd Research) and dried overnight under vacuum.

\section{Characterization}

${ }^{1} H$ NMR spectra were recorded on a Varian MERCURY (300 MHz) using deuterochloroform as a reference or an internal deuterium lock. The chemical shift data for each signal are given in units of $\delta(\mathrm{ppm})$ relative to tetramethylsilane (TMS) where $\delta$ (TMS $)=0$, and are referenced to the solvent residual. Infrared spectra were collected with a Perkin Elmer 1000 FT-IR spectrometer in $\mathrm{KBr}$ and were recorded in reciprocal centimeters ( $\mathrm{cm}^{-1}$, wavenumbers). The PAE molecular weights were determined by Gel Permeation Chromatography (GPC) running with THF as the eluent versus polystyrene standards (PolySciences) using a Hewlett Packard series 1100 HPLC instrument equipped with a Plgel $5 \mathrm{~mm}$ Mixed-C (300 x $7.5 \mathrm{~mm})$ column. TGA was performed on a Perkin-Elmer TGA7 under $\mathrm{N}_{2}$ at a rate of $10{ }^{\circ} \mathrm{C} /$ minute. DSC was on a Perkin-Elmer DSC7 under $\mathrm{N}_{2}$ at a rate of $10{ }^{\circ} \mathrm{C} /$ minute. UV-visible absorption spectra were measured with a Cary $50 \mathrm{UV/Visible} \mathrm{spectrometer.} \mathrm{Transmission} \mathrm{electron} \mathrm{microscopy} \mathrm{(TEM)} \mathrm{was}$ carried out with a JEOL 2010 microscope operating at $200 \mathrm{keV}$, equipped with an elemental analysis system.

Comonomer b: A literature preparation was used to synthesize the 2,5-bis(4fluorophenyl)-1,3,4-oxadiazole monomer b. ${ }^{1}$

General Procedure for preparation of Poly(aryl ether)s: A Schlenk flask was loaded with the hydroquinone, a fluorinated monomer, and $\mathrm{K}_{2} \mathrm{CO}_{3}$ (2.3 equiv.) in DMA. The flask was frozen, evacuated, and thawed under positive argon pressure three times. The Schlenk tube was sealed and the solution was heated to $170{ }^{\circ} \mathrm{C}$ overnight. Acetic anhydride was added, followed by precipitation of the reaction solution into methanol. The polymer was collected by vacuum filtration and washed repeatedly with water and methanol. The white PAE was dried in vacuo overnight with heating.

${\mathrm{PAE}-\mathrm{SO}_{2}}_{2}$ - Triptycene-1,4-hydroquinone (172 mg, $0.6 \mathrm{mmol}$ ), bis(4-fluorophenyl) sulfone (153 mg, $0.6 \mathrm{mmol}$ ), $\mathrm{K}_{2} \mathrm{CO}_{3}$ (193 mg, $1.4 \mathrm{mmol}$ ), DMA (5 mL), yield (279 mg, 93 \%). IR (KBr pellet) v1325-1295 (SO ${ }_{2}$ antisym str.), 1230 (-C-O-C-), 1150-1105 ( $\mathrm{SO}_{2}$ 
sym str.), $565 \mathrm{~cm}^{-1}$ ( $\mathrm{SO}_{2}$ scissor mode). ${ }^{1} \mathrm{H}$ NMR $\left(300 \mathrm{MHz}, \mathrm{CDCl}_{3}\right) \delta_{\mathrm{H}} 7.92-7.89(4 \mathrm{H}$, br signal), 7.05-7.02 (4H, br signal), 6.94-6.90 (8H, br signal), 6.68 (2H, br s), $5.42(2 \mathrm{H}$, br s).

PAE-Oxa - Triptycene-1,4-hydroquinone (172 mg, $0.6 \mathrm{mmol}$ ), 2,5-bis(4-fluorophenyl)1,3,4-oxadiazole (155 mg, $0.6 \mathrm{mmol}$ ), $\mathrm{K}_{2} \mathrm{CO}_{3}$ (193 mg, $1.4 \mathrm{mmol}$ ), DMA (5 mL), yield (206 mg, $68 \%$ \%). IR (KBr pellet) $v 1610$ (-C=N-), 1230 (-C-O-C-), 1010, $960 \mathrm{~cm}^{-1}$ (oxadiazole). ${ }^{1} \mathrm{H}$ NMR (300 MHz, $\left.\mathrm{CDCl}_{3}\right) \delta_{\mathrm{H}} 8.14-8.11(4 \mathrm{H}$, br signal), 7.28-7.25 $(4 \mathrm{H}$, br signal), 7.04-7.02 (8H, br signal), 6.81 (2H, br s), 5.64 (2H, br s).

PAE-Oxa-SO ${ }_{2}$ - Triptycene-1,4-hydroquinone (172 mg, $0.6 \mathrm{mmol}$ ), bis(4-fluorophenyl) sulfone (114 mg, $0.45 \mathrm{mmol}$ ), 2,5-bis(4-fluorophenyl)-1,3,4-oxadiazole (39 mg, 0.15 mmol), $\mathrm{K}_{2} \mathrm{CO}_{3}$ (193 mg, $1.4 \mathrm{mmol}$ ), DMA (5 mL), yield (275 mg, $91 \%$ ). IR (KBr pellet) $v$ 1325-1295 ( $\mathrm{SO}_{2}$ antisym str.), 1236 (-C-O-C-), 1154-1105 ( $\mathrm{SO}_{2}$ sym str.), $563 \mathrm{~cm}^{-1}$ $\left(\mathrm{SO}_{2}\right.$ scissor mode). ${ }^{1} \mathrm{H}$ NMR $\left(300 \mathrm{MHz}, \mathrm{CDCl}_{3}\right) \delta_{\mathrm{H}}$ 8.13-8.08, 7.94-7.87, 7.28-7.22, 7.05-6.90, 6.85-6.68, 5.63, 5.60, 5.45-5.40. All relatively broad signals.

\section{References:}

(1) Toshima N.; Yonezawa, T. New. J. Chem. 1998, 1179. 